\title{
AVALIACCÕES \\ EDUCACIONAIS E SEUS \\ REFLEXOS EM AÇÕES \\ FEDERAIS E NA MÍDIA ELETRÔNICA
}

JOÃO LUIZ HORTA NETO

* Este trabalho, fruto da pesquisa de doutorado elaborado pelo autor sob a orientação da Professora Silvia Cristina Yannoulas, recebeu apoio da Coordenação de Aperfeiçoamento de Pessoal de Nível Superior (Capes) dentro do programa Observatório da Educação.

\section{RESUMO}

O objetivo deste trabalho é discutir os usos dos resultados das avaliações educacionais brasileiras por algumas ações desenvolvidas pelo governo federal no Plano de Desenvolvimento da Escola, seus possíveis reflexos no trabalho da escola e como a mídia eletrônica escrita vem tratando do tema. Discute-se o direito à aprendizagem e o processo de accountability, eixos das ações governamentais nos últimos anos. A seguir, analisase o desenvolvimento dos testes aplicados aos alunos do ensino fundamental entre 1990 e 2012, identificando seus instrumentos e principais resultados. Devido à atual importância dos testes como um indicador de qualidade educacional, investigou-se, ainda, como essa qualidade é tratada pelos meios de comunicação eletrônicos. Conclui-se que os testes têm sido utilizados basicamente como instrumento para definir desempenhos das escolas, com reflexos indesejáveis sobre o trabalho que elas e seus profissionais realizam, na medida em que o foco das ações tem sido buscar melhorar o desempenho nos testes.

PALAVRAS-CHAVE AVALIAÇÃO EDUCACIONAL • PROVA BRASIL・ PROVINHA BRASIL - PLANO DE DESENVOLVIMENTO DA ESCOLA. 


\section{RESUMEN}

El objetivo de este trabajo es discutir los usos de los resultados de las evaluaciones educacionales brasileñas por intermedio de algunas acciones desarrolladas por el gobierno federal en el Plano de Desenvolvimento da Escola, sus posibles reflejos en el trabajo de la escuela y la forma en que los medios electrónicos escritos vienen tratando el tema. Se discute el derecho al aprendizaje y el proceso de accountability, ejes de las acciones gubernamentales en los últimos años. A seguir se analiza el desarrollo de las pruebas aplicadas a los alumnos de la educación fundamental entre 1990 y 2012, identificando sus instrumentos y principales resultados. Debido a la actual importancia de las pruebas como un indicador de calidad educativa, se investigó asimismo cómo dicha calidad es tratada por los medios de comunicación electrónicos. Se concluye que las pruebas han sido utilizadas básicamente como instrumentos para definir desempeños de las escuelas, con reflejos indeseables sobre el trabajo que ellas y sus profesionales realizan, ya que el foco de las acciones ha sido intentar mejorar el desempeño en las pruebas.

PALABRAS CLAVE EVALUACIÓN EDUCATIVA - PROVA BRASIL • PROVINHA BRASIL • PLANO DE DESENVOLVIMENTO DA ESCOLA.

\section{ABSTRACT}

The purpose of this study is to discuss the uses of the results of Brazilian educational evaluations for some actions developed by the Plano de Desenvolvimento da Escola, their possible consequences in the work of schools and how the electronic written media has been approaching this topic. The right to learning and the process of accountability, axes of governmental actions in recent years, are discussed. Next, the development of the tests given to elementary school students between 1990 and 2012, identifying their instruments and principal results, are analyzed. Due to the current importance of the tests as an indicator of educational quality, how electronic communications media treat this quality is also investigated. It is concluded that the tests have been used, basically, as an instrument to define school performance, with undesirable consequences for the work that they and their professionals are doing, such that the focus of the actions has been to seek to improve the performance on the tests.

KEYWORDS EDUCATIONAL EVALUATION - PROVA BRASIL • PROVINHA BRASIL・SCHOOL DEVELOPMENT PLAN. 


\section{INTRODUÇÃO}

Avaliar é um conceito em si mesmo polissêmico, algumas vezes confundido com os instrumentos usados para medir resultados educacionais, geralmente por meio de testes. Como a atividade de avaliar vai além de simplesmente medir e divulgar os resultados, neste trabalho será usada a expressão "teste avaliativo" em referência ao instrumento de medida utilizado em avaliações educacionais.

Discutir o desempenho dos sistemas educacionais a partir de testes exige clareza sobre todo o processo de sua realização e aplicação e de seu sentido. Essa não é uma discussão trivial, pois discute a função social da escola e as modificações pelas quais ela vem passando ao longo do tempo e o papel do Estado nesse processo (HORTA NETO, 2010).

$\mathrm{O}$ desenvolvimento deste trabalho baseou-se em quatro hipóteses: tem havido um excesso de testes avaliativos, na expectativa de que sua aplicação e os resultados obtidos impulsionem desempenhos crescentes; apesar de os testes terem a capacidade de oferecer informações importantes para a melhoria da gestão dos sistemas de ensino, a ênfase nos 
últimos anos tem sido na sua utilização para melhorar o desempenho do aluno; pode estar havendo um estreitamento curricular, na medida em que o ensino esteja voltado para o que é demandado pelos testes; os resultados dos testes não têm sido utilizados como balizadores das ações desenvolvidas pelo governo federal, mas sim como balizadores para as transferências voluntárias da União. Essas hipóteses serão discutidas ao longo do texto.

\section{O CRESCENTE AUMENTO NO NÚMERO DOS TESTES}

No Brasil, nos últimos anos, tem-se ampliado o número de governos municipais e estaduais e de gestores das redes privadas de ensino que utilizam testes elaborados externamente para medir o desempenho dos estudantes. Isso pode ser observado no Gráfico 1, que apresenta o avanço do número de governos estaduais que contam com avaliações próprias no período entre 1992 e 2013.

GRÁFICO 1 - Número de governos estaduais, por ano, que contavam com testes avaliativos próprios - 1992 a 2013

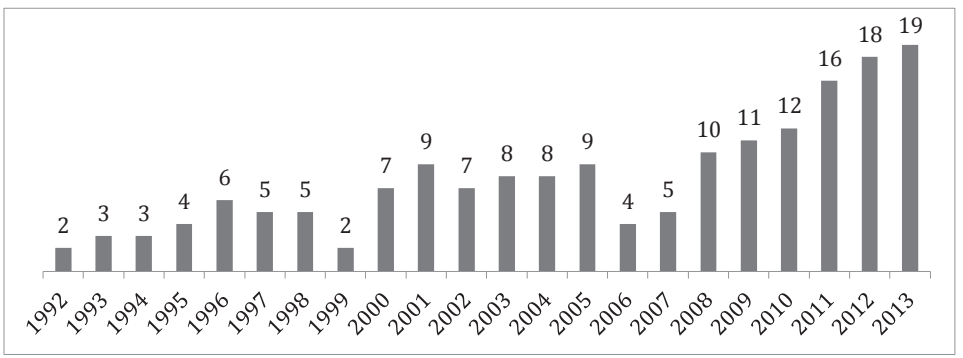

Fonte: Brooke, Cunha, Faleiros (2011) e levantamento do autor junto às Secretarias Estaduais de Educação.

Em 1992, os estados de Minas Gerais e Ceará começaram a aplicação dos testes avaliativos. Em 1995, além dos dois estados, desenvolveu-se o teste no Mato Grosso do Sul e em São Paulo (BROOKE; CUNHA; FALEIROS, 2011). Em 2012, 18 dos 27 estados da federação aplicavam testes cognitivos a seus alunos. Eram os seguintes os estados, e os nomes dos seus respectivos testes: Acre - Sistema Estadual de Avaliação da Aprendizagem Escolar (Seape); Alagoas - Sistema de Avaliação 
Educacional de Alagoas (Saveal); Amazonas - Sistema de Avaliação do Desempenho Educacional do Amazonas (Sadeam); Bahia - Sistema de Avaliação Baiano de Educação (Sabe); Ceará - Sistema Permanente de Avaliação da Educação Básica do Ceará (Spaece); Espírito Santo - Programa de Avaliação da Educação Básica do Espírito Santo (Paebes); Goiás - Sistema de Avaliação Educacional do Estado de Goiás (Saego); Minas Gerais - Sistema Mineiro de Avaliação da Educação Pública (Simave); Mato Grosso do Sul - Sistema de Avaliação da Rede Pública de Mato Grosso do Sul (Saems); Paraíba - Sistema de Avaliação da Educação da Paraíba (Avaliando IDEPB); Paraná - Sistema de Avaliação da Educação Básica do Paraná (Saep); Pernambuco - Sistema de Avaliação Educacional de Pernambuco (Saepe); Piauí - Sistema de Avaliação Educacional do Piauí (Saepi); Rio de Janeiro - Sistema de Avaliação da Educação do Estado do Rio de Janeiro (Saerj); Rio Grande do Sul - Sistema Estadual de Avaliação Participativa (Seap); Rondônia - Sistema de Avaliação Educacional de Rondônia (Saero); São Paulo - Sistema de Avaliação do Rendimento Escolar do Estado de São Paulo (Saresp); Tocantins - Sistema de Avaliação da Educação do Tocantins (Salto). Em 2013, o Pará anunciou a criação do Sistema Paraense de Avaliação Educacional (Sispae). Estão em processo de desenvolvimento o Sistema Maranhense de Avaliação do Desempenho Escolar (Simade), no Maranhão, e um teste avaliativo no Distrito Federal, que já havia criado, depois descontinuado, um sistema próprio anos atrás. Seguindo esse ritmo, é possível que os estados que ainda não possuem testes próprios anunciem os seus em curto espaço de tempo.

Analisando-se o Gráfico 1, percebe-se, desde 1992, uma tendência de crescimento do número de estados constituindo seus sistemas próprios de avaliação. Entretanto, antes de 2008, o crescimento apontado sofre algumas interrupções e quedas, firmando-se a partir de então. Cabe apontar dois momentos importantes. Em 2006, um ano após a primeira edição da Prova Brasil, o número de estados cai a menos da metade, o que faz sentido, pois, se o teste federal passou a ser censitário, muitos estados deixaram de aplicar os seus. O interessante é que, em 2008, ano seguinte à criação do 
Índice de Desenvolvimento da Educação Básica (Ideb), dobra o número de estados constituindo sistemas próprios de avaliação, e, a partir de então, o número vem crescendo ano a ano, sugerindo que a criação do indicador de alguma forma estimulou os estados a desenvolverem seus testes.

A maior parte desses testes segue o mesmo modelo daquele instituído pelo governo federal para o Sistema de Avaliação da Educação Básica (Saeb)/Prova Brasil, tanto em termos das áreas de conhecimento e anos escolares testados, bem como na maior parte das habilidades cognitivas escolhidas para compor as Matrizes de Referência dos testes. Se já existem dados coletados pelo governo federal de forma censitária, questiona-se a razão de obtê-los novamente pelos governos subnacionais.

Obtidos os desempenhos das escolas, alguns governos começaram a utilizar estratégias de premiação com o objetivo declarado de estimular resultados escolares cada vez melhores. Baseados também nos resultados dos testes, os órgãos gestores passam a instituir programas de incentivos e pagamento de bônus para a equipe escolar por atingir metas, metas essas normalmente fixadas de forma unilateral. Outras estratégias conhecidas são a distribuição de prêmios e o sorteio de brindes aos alunos que mais se destacam nos testes.

No caso do governo federal, desde 1988, ano dos primeiros estudos para a aplicação do Sistema de Avaliação da Educação Básica (Saeb), realizado regularmente desde 1990, vem aumentando a quantidade de testes aplicados e o número de alunos testados. Depois do Saeb, criaram-se a Prova Brasil, em 2005, a Provinha Brasil, em 2008, e a Avaliação Nacional de Alfabetização (ANA) em 2013. Outros exames foram sendo criados e aprimorados: o Exame Nacional dos Estudantes do Ensino Médio (Enem) e o Exame Nacional de Certificação de Competências da Educação de Jovens e Adultos (Encceja). Como se percebe, diversos instrumentos que o governo federal tem a sua disposição, gerando grande volume de dados sobre o desempenho dos alunos, todos produzidos pelo Instituto Nacional de Estudos e Pesquisas Educacionais Anísio Teixeira (Inep). Contando apenas o Saeb/Prova Brasil, foram aplicados quase 19 milhões de testes aos alunos desde 1990 (HORTA NETO, 2013). 
Além de criar testes avaliativos próprios, o Brasil vem participando de alguns estudos internacionais, como o Programme for International Student Assessment (Pisa), patrocinado pela Organização para a Cooperação e Desenvolvimento Econômico (OCDE), e o Laboratório Latino Americano de Evaluación de la Calidad de la Educación (LLECE), programa coordenado pela Oficina Regional de Educación para América Latina y El Caribe (Orealc), entidade ligada à Unesco.

Nessa profusão de testes nacionais e internacionais, pode acontecer de uma mesma escola ter seus alunos testados por diversas vezes ao longo do ano, envolvendo pré-testes, utilizados para avaliar a qualidade dos itens que comporão os testes, e testes municipais, estaduais, nacionais e internacionais.

Junto com essa quantidade de testes, cria-se, também, um mercado da avaliação educacional que está em franco desenvolvimento no Brasil, oferecendo livros e consultorias com o objetivo de preparar as escolas para a participação nesses testes, assim como empresas e instituições desenvolvendo instrumentos para testar o desempenho das escolas e seus alunos e vendendo seus serviços para as secretarias estaduais e municipais ou para as escolas, nesse caso, privadas.

Para compreender melhor esse movimento na direção do incremento do número de testes, é importante discutir dois conceitos que se entrecruzam: o direito à aprendizagem e o accountability.

\section{O DIREITO À APRENDIZAGEM E O PROCESSO DE ACCOUNTABILITY}

A educação, como um direito social, está presente na Constituição brasileira de 1988, por ser inerente à cidadania e aos direitos humanos, tendo sido declarada como direito do cidadão e dever do Estado. No entanto, não é possível haver garantia do direito à educação sem assegurar que sua oferta atenderá às necessidades dos beneficiados, e isso implica o papel ativo e responsável do Estado, formulando políticas e obrigando-se a oferecer ensino em igualdade de condições para todos. Aliás, a própria Constituição prevê que essa 
igualdade de condições se materialize, garantindo-se um padrão de qualidade.

Apesar de presente em nossa Constituição, o termo qualidade nunca foi explicitado. No Brasil, dado à sua polissemia, pode-se observar que, com o passar do tempo, vários foram os significados que lhe foram atribuídos: associada à ampliação da oferta de vagas, acarretando, a partir da década de 1940, a construção de prédios escolares; a partir do final da década de 1970 e durante a década de 1980 , associada à permanência com sucesso na escola; a partir da década de 1990, associada à melhoria do desempenho cognitivo dos alunos, medida pela aplicação de testes avaliativos (OLIVEIRA; ARAÚJO, 2005). Nesse último período, como pode ser verificado pelos dados apresentados no Gráfico 1, o centro das atenções dos governos tem sido aumentar a quantidade de testes avaliativos. Uma das hipóteses que explicaria esse aumento seria a de que, a partir dos seus resultados, toda a comunidade escolar se mobilizasse por si, ou por pressão das famílias dos alunos, em busca de desempenhos cada vez melhores. Como consequência, a atenção do poder público estaria centrada em estratégias que garantissem melhorias nos resultados dos testes, e não em aprimorar o processo educacional. Dessa forma, a avaliação, em seu sentido amplo, perde seu sentido como instrumento da prática pedagógica e apequena-se.

Como o desempenho ganha a centralidade, o próprio direito à educação, envolvendo a garantia de acesso e permanência para todos e ensino de qualidade uniforme também para todos, trazendo em seu bojo o potencial de emancipar o indivíduo e de nivelar as desigualdades dos que frequentam a escola, acaba também se apequenando. Nos últimos anos, tem-se ouvido muito falar sobre o direito à aprendizagem, expressão que parece ter sido primeiramente utilizada pelo Unicef em duas publicações (FUNDO DAS NAÇÕES UNIDAS PARA A INFÂNCIA; BRASIL; UNIÃO DOS DIRIGENTES MUNICIPAIS DE EDUCAÇÃO, 2008; BRASIL; FUNDO DAS NAÇÕES UNIDAS PARA A INFÂNCIA, 2007), e que pouco tempo depois, passou a ser utilizada pelo Ministério da Educação (MEC) quando lançou documento sobre os direitos de 
aprendizagem para o ciclo de alfabetização (BRASIL, 2012). Dessa forma, algo que no espírito da legislação educacional se relaciona com a formação básica do cidadão, em íntima relação com o direito à educação, transmuta-se em direito à aprendizagem da leitura, da escrita e do cálculo, conforme se depreende da leitura do documento citado.

A aprendizagem não pode ser compreendida fora do direito à educação, assim como do ensino de qualidade, de prédios escolares adequados e de outros fatores que permitem garantir esse direito. Reduzir o direito à educação, um direito tão amplo e fundamental à construção da cidadania, a algo restrito apenas à aprendizagem, é um equívoco conceitual e político. Conceitual, porque o direito à educação é muito mais amplo do que a aprendizagem; político, porque ainda inexistem condições iguais para todas as escolas brasileiras, e retirar o foco disso é como aceitar a imensa desigualdade existente. Mesmo que o objetivo fosse usar uma expressão forte para dar visibilidade a um problema que merece ser atacado - as dificuldades na aprendizagem -, isso não justificaria a interpretação reducionista dada à Lei.

Independentemente das razões que levaram à formulação do termo direito à aprendizagem, o fato é que por tal formulação se justificaria, pelo menos em parte, o aumento dos testes. Isso porque, se a aprendizagem da leitura, da escrita e do cálculo é um direito, os testes para medir a aprendizagem seriam os instrumentos para verificar o cumprimento desse direito. Assim, a aprendizagem escolar se restringiria àquilo que pode ser medido pelos testes, novamente uma redução de algo muito maior, pois para que a aprendizagem ocorra é necessário que se desenvolvam também diversas outras habilidades que nem sempre podem ser medidas pelos testes avaliativos.

Ao medir, por testes, se o direito à aprendizagem está ou não sendo atendido, o passo seguinte nessa lógica seria expor publicamente os resultados, premiando aquelas instituições e seus profissionais que realizam bem seu trabalho, ou apontar aqueles que não o fazem, na esperança de que nas próximas medições, principalmente por conta da pressão dos resultados, eles sejam melhores do que os anteriores. 
Nesse processo, muitas vezes deixa-se a escola e seus profissionais expostos à própria sorte, como se não necessitassem de apoio para desenvolver suas atividades.

Essa lógica perversa faz parte de uma série de políticas que tomam por base o accountability e que se espalha pelo mundo. A esse fenômeno, Sahlberg (2011) dá a sugestiva alcunha de Germ (germe), abreviatura de Global Educational Reform Movement (Movimento Global de Reforma Educacional). Segundo o autor, esse germe viaja com os especialistas, a mídia e os políticos, espalhando-se pelo mundo, trazendo como consequências mal-estar entre os professores e menor aprendizagem para as crianças. Entre os sintomas indicados pelo autor como causas das doenças ocasionadas por esse germe, duas se destacam: a maior competição na educação, baseada na crença de que a educação se aprimora quando as escolas competem entre si, criando o que Afonso $(1999,2005)$ chamou de Quase-Mercado; a forte responsabilização das escolas e a busca da efetividade do professor, ambos tendo por base os testes avaliativos aplicados aos estudantes.

Diversos autores sustentam que o aumento dos testes avaliativos têm causado efeitos danosos e indesejados, como o aumento do ensino focado nos testes, o estreitamento do currículo para priorizar a leitura e a matemática e a aproximação da pedagogia a uma instrução mecânica (RAVITCH, 2010, 2013; SAHLBERG, 2011; HORTA NETO, 2013).

Sahlberg (2011) afirma que existe outra forma de aprimorar a aprendizagem e cita o exemplo da Finlândia. Segundo o autor, o país se fixa em um ensino e aprendizado customizados, ao invés de modelos estandardizados; tem como foco o aprendizado criativo, envolvendo, além do estudo das diferentes áreas do conhecimento humano, as habilidades necessárias para o desenvolvimento da personalidade do indivíduo, em vez de um ensino com foco em leitura, matemática e ciências; estimula um currículo baseado na escola e desenvolvido pelos professores, em que os riscos e as incertezas quanto ao ensino e à aprendizagem são aceitáveis, em vez de um currículo escolar prescritivo; baseia suas ações na responsabilidade compartilhada e na confiança em vez de accountability baseado em testes e controle. 
No caso brasileiro, o governo federal tem ampliado a cada ano a abrangência e a quantidade de testes avaliativos voltados para a educação básica, uma ação que vem recebendo destaque em relação a outras, como a formação de professores para atuar nesse nível de ensino, sua atribuição legal. Para justificar essa afirmação, optou-se por acompanhar, tomando por base o ensino fundamental, a evolução do Saeb, a criação de novos testes, algumas das ações desenvolvidas pelo governo federal e seus reflexos sobre os sistemas de ensino e as escolas.

\section{A EVOLUÇÃO DOS TESTES PARA AFERIR O DESEMPENHO DO SISTEMA EDUCACIONAL: OS OBJETIVOS INICIAIS E SUAS ALTERAÇÕES}

Entre as décadas de 1960 e 1980, uma série de acontecimentos no Brasil contribuiu para o desenvolvimento de expertise na área de avaliação educacional. O primeiro deles, sem dúvida, foi o surgimento dos vestibulares unificados na década de 1960 em São Paulo.

Esses vestibulares unificados alteraram a lógica anterior, que estipulava uma nota mínima para o ingresso na faculdade. Pela nova lógica, a seleção de candidatos é feita até o limite do número de vagas e, para tanto, novos instrumentos de medida começam a ser desenvolvidos. O sucesso desse modelo e a utilização dos testes objetivos fizeram com que os itens de múltipla escolha ganhassem destaque nos livros didáticos, passando a ser amplamente utilizados pelos educadores (GATTI, 2002).

Para elaborar instrumentos cada vez mais sofisticados e confiáveis, capazes de dar conta do desafio de selecionar, entre milhares de candidatos, aqueles mais bem preparados para enfrentar a educação superior, foi necessário o desenvolvimento de equipes cujo objetivo fosse criar instrumentos de medida sofisticados e aprimorar a elaboração dos testes. Criaram-se, assim, as bases de conhecimento para as etapas seguintes. 


\section{SAEB E PROVA BRASIL}

Pode-se classificar o Saeb pelas três fases que o modificam substancialmente, apesar de outros autores proporem diferentes divisões (BONAMINO; SOUZA, 2012). A primeira fase, a dos primeiros estudos até sua implantação, entre 1980 e 1993, começou com as pesquisas iniciadas durante o Projeto Edurural, passou pela aplicação piloto de 1988, e envolveu as aplicações que ocorreram nos dois ciclos seguintes, de 1991 e 1993. A segunda fase, entre 1995 e 2003, envolvendo o esforço para aprimorar seus instrumentos, foi iniciada com o uso da Teoria da Resposta ao Item (TRI), no ciclo de 1995; a construção das Matrizes de Referências, no ciclo de 1997 e a consolidação desse modelo metodológico nos três próximos ciclos, entre 1999 e 2003. A terceira fase se iniciou no ciclo de 2005, perdurando até os dias de hoje, com a transformação do teste amostral em censitário.

O que chama a atenção nesse processo é que não houve descontinuidade no desenvolvimento e no amadurecimento do Saeb, processo iniciado na época do regime militar, durante o governo de João Figueiredo (1979-1985), e que atravessou os governos de José Sarney (1985-1990), Fernando Collor (1990-1992), Itamar Franco (1992-1995), os dois governos de Fernando Henrique Cardoso (1995-2003), os dois governos de Luiz Inácio Lula da Silva (2003-2011) e o governo de Dilma Rousseff. Foram governos com diferentes orientações políticas, mas em todos se privilegiou a realização de medidas de desempenho cognitivo como uma das estratégias para aprimorar a qualidade da educação. O que mudou ao longo do tempo foi a abrangência da avaliação e os usos que se fizeram de seus resultados.

Na primeira fase, com o envolvimento de Jacobo Waiselfitz, Heraldo Vianna e Bernadete Gatti, a maior preocupação era envolver os professores na elaboração dos itens do teste e em uma discussão coletiva dos resultados obtidos. Por causa disso, apesar de Heraldo Vianna reconhecer a importância do uso da TRI, utilizou-se a Teoria Clássica dos Testes para apresentar os resultados dos testes, pois essa forma de apresentação, dada em função do número de acertos neles, facilitaria a compreensão dos professores (VIANNA, 1990). 
Além disso, a escolha dos anos escolares a serem testados $\left(1^{\mathrm{a}}\right.$, $3^{\mathrm{a}}, 5^{\mathrm{a}}$ e $7^{\mathrm{a}}$ séries) recaiu sobre aqueles em que, reconhecidamente, os alunos apresentavam maiores problemas, e que, por isso, precisariam ser mais bem investigados (KORTE; NASH, 1995).

A segunda fase inaugura a busca pela excelência da medida, abandonando progressivamente a preocupação com a compreensão dos resultados, que passam a ser apresentados em uma escala que vai de 0 a 500 pontos, permitindo comparações a cada ciclo. Outra característica nessa fase foi a alteração dos anos escolares testados ( $4^{\mathrm{a}}$ e $8^{\mathrm{a}}$ séries) com a justificativa de que dessa forma seria possível garantir uma maior homogeneidade nos conteúdos escolares ensinados, algo que seria muito disperso na escolha dos anos escolares anteriores.

O processo de accountability se aprofunda a partir da terceira fase, iniciada em 2005, ano em que os testes, agora chamados de Prova Brasil, são aplicados de forma quase censitária às escolas públicas, e seus resultados passam a compor um índice destinado a aferir a qualidade da educação básica, o Ideb.

Os Gráficos 2 e 3 mostram como variaram as proficiências médias em Língua Portuguesa e Matemática, respectivamente, no Saeb e na Prova Brasil entre 1995 e 2011.

GRÁFICO 2 - Evolução da proficiência média em Língua Portuguesa no Saeb/Prova Brasil - escolas públicas - 1995 a 2011

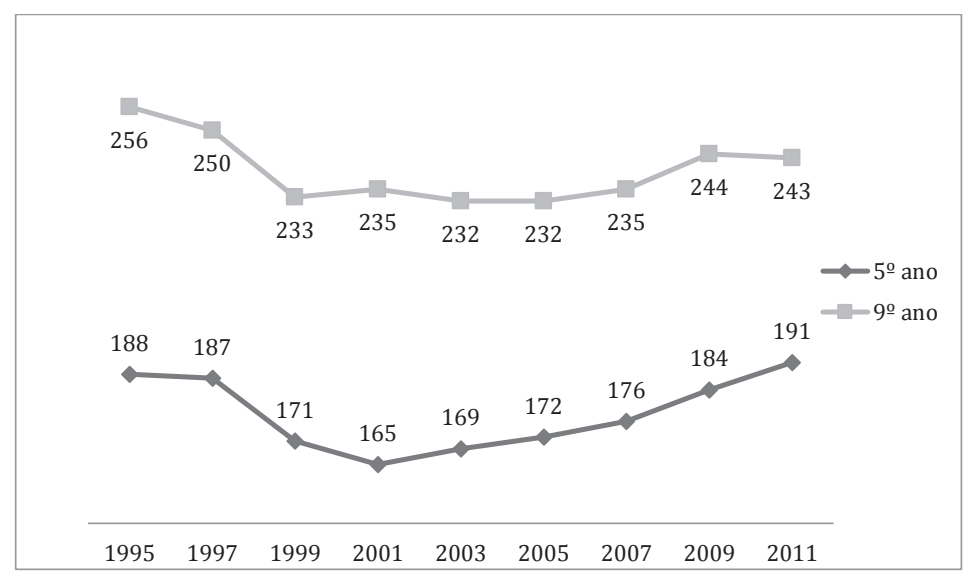

Fonte: Elaboração do autor com base nos dados do Inep (BRASIL, 2011). 
GRÁFICO 3 - Evolução da proficiência média em Matemática no Saeb/Prova Brasil - escolas públicas - 1995 a 2011

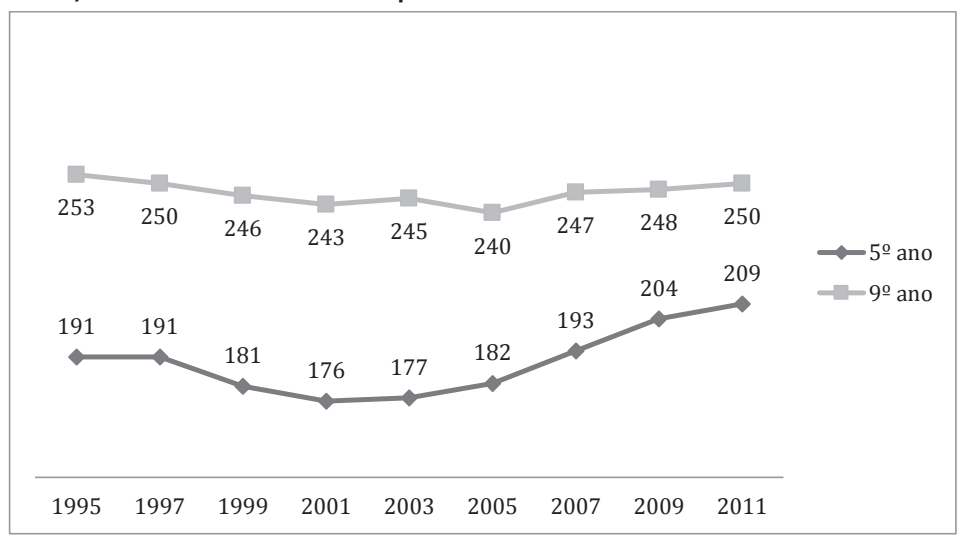

Fonte: Elaboração do autor com base nos dados do Inep (BRASIL, 2011).

Nos dois gráficos, é apresentada a variação da proficiência obtida nos testes. Para começar a análise das proficiências no contexto em que foram colhidas, é preciso ter em mente que em toda a média podem esconder-se muitas disparidades, portanto ela não é a medida mais transparente de todas.

Serão discutidos três períodos: de 1995 a 2001, o ano de 2003 e de 2005 a 2011.

O período de 1995 a 2001 foi marcado pela queda constante das proficiências em todos os anos escolares e em ambas as áreas. Esse período coincide com os dois governos Fernando Henrique Cardoso, e foi marcado por uma grande discussão envolvendo a queda da qualidade da educação pela significativa inclusão das camadas mais pobres da população na escola. Apesar de ser uma hipótese plausível, não se sabe de nenhum estudo que tenha sido feito para sustentá-la. No entanto, isso poderia explicar a queda da proficiência nos anos iniciais do ensino fundamental, mas não a queda nos anos finais, a menos que se imagine que o movimento de entrada na escola foi acompanhado por outro, de retorno a ela.

Em 2003, já no primeiro governo de Luiz Inácio Lula da Silva, o teste não sofre nenhuma alteração, e nos anos iniciais do ensino fundamental há uma melhora que, na época, o relatório técnico creditou às políticas implantadas pelo novo governo. Mas como explicar também as melhoras no $9^{\circ}$ ano? 
O ano de 2005, quando começa a Prova Brasil, marca o início da trajetória ascendente nas proficiências para os anos iniciais e finais do ensino fundamental, apesar de nos anos finais o crescimento ser de magnitude menor. Em 2007 entra em cena o Ideb, e o MEC divulga em seu site um simulado para ajudar os professores e as escolas a se prepararem para o teste. Nesse ano também, os gestores recebem, meses antes da realização do teste, o valor do Ideb de 2005 das redes e das escolas e as metas que deveriam ser atingidas no Ciclo de 2007. Será que o aumento das proficiências a partir de 2005 estaria melhorando a qualidade do ensino oferecido e isso se refletiria na elevação das proficiências medidas?

Sem pretender aqui ser exaustivo na discussão, algumas hipóteses podem ser levantadas. A primeira é que, encerrado o fluxo acelerado de entrada na escola, tenha havido uma acomodação, e, com isso, tenha sido possível melhorar o atendimento aos alunos. Outra é que o aumento no valor dos programas de transferência de renda, capitaneados pelo Programa Bolsa Família, e o aumento das famílias beneficiadas tenham contribuído para retirar da miséria muitas crianças e jovens, com reflexos na aprendizagem. Efeito semelhante poderia ser creditado ao aumento da renda da população, fruto do período de crescimento econômico vivido nos últimos anos. Até aqui, referimo-nos aos efeitos externos que impactam a aprendizagem, positivos e desejáveis. Outra hipótese é que o aumento da escolaridade para nove anos, a partir de 2006, colocando a criança mais cedo em contato com um ambiente de aprendizagem, possa também estar contribuindo para o aumento das proficiências, mas, nesse caso, por ser uma medida recente, a contribuição ainda deve ser mínima.

Pode ser também que houvesse um problema de gestão nas redes e nas escolas, e, com o impacto das pressões por melhores desempenhos, os gestores tenham desenvolvido estratégias para dar mais apoio às escolas, e esse apoio tenha chegado aos professores, estando eles, assim, mais preparados para melhorar a aprendizagem de seus alunos. Por fim, uma hipótese, que se lê nas entrelinhas das matérias jornalísticas e nas declarações de alguns gestores educacionais, 
é a de que os gestores escolares e os professores estivessem fazendo "corpo mole", algo que o Ideb estaria denunciando. Com isso, eles começaram a se esforçar mais, alcançando melhores resultados. Até aqui todas as hipóteses levantadas refletiriam em benefício das crianças e dos jovens.

Mas existem também hipóteses que trariam prejuízos ao ensino. Pode ser que, por conta da pressão por melhorias dos indicadores das escolas, esteja havendo uma redução do currículo, que estaria moldando-se às Matrizes de Referências dos testes. Além disso, por conta dessa mesma pressão, as escolas podem centrar uma boa parte de suas atividades na preparação para o teste, principalmente pela aplicação de simulados, aproveitando os próprios modelos disponibilizados pelo MEC. Esses dois fatores também podem estar na raiz da explicação para o crescimento mais acelerado das proficiências nos anos iniciais do que nos finais. Como nos anos iniciais funciona a unidocência, é mais fácil para o professor organizar seu tempo e, dessa forma, preparar melhor seus alunos para o teste, algo mais complicado na etapa seguinte, com vários professores de diferentes áreas. Essas práticas, além de não colaborarem para a aprendizagem, estariam contribuindo para a homogeneização do ensino.

Todas essas hipóteses devem ser averiguadas, mas, no caso desse trabalho, a hipótese da preparação para o teste é investigada mais a frente.

\section{PROVINHA BRASIL}

A Provinha Brasil, aplicada pela primeira vez em 2008, testa os alunos no segundo ano de escolaridade nas áreas de Língua Portuguesa e Matemática no início e no final de cada ano, utilizando os chamados Testes 1 e 2, respectivamente, em cada um desses momentos. O teste é composto, em sua maioria, por itens de múltipla escolha, divididos em três tipos: aqueles em que o professor lê totalmente o item e os alunos marcam a alternativa correta; outros em que o professor lê uma parte do item, o aluno, a outra, e, então, assinala a resposta correta; por fim, itens que o aluno lê sozinho e marca a alternativa correta. Além desses, constam do teste 
três outros itens, sendo que em dois deles o professor faz um ditado de palavras, e, no terceiro, faz um ditado de uma frase. Para os itens de múltipla escolha, são fornecidos os gabaritos, e, para os três itens do ditado, é fornecida uma grade de correção com seis possibilidades, em que três delas indicam aquelas consideradas corretas. Foram definidos cinco níveis de proficiência, utilizados para classificar os alunos segundo seu estágio de alfabetização, numerando-os de 1 a 5 , e a cada um deles se associou um número de acertos, mas apenas para os itens de múltipla escolha. Para auxiliar a compreensão dos professores sobre os resultados do teste, foi apresentada uma interpretação pedagógica de cada um dos níveis.

Essa forma de apresentar os resultados levanta algumas preocupações. Primeiramente, o problema de uma classificação como essa é enquadrar um processo tão dinâmico e complexo como a alfabetização em uma determinada categoria, descrevendo-o a partir de itens construídos com base em uma Matriz de Referência que não necessariamente reflete o currículo praticado na escola e o definido pelo sistema de ensino em que a escola está inserida. Além disso, para o professor, o processo parece uma mágica: como associar um número de acertos de itens, independentemente do item que o aluno acertou, com uma etapa do processo de alfabetização que apresenta uma descrição tão fechada? Assim, apesar de, na Provinha Brasil, o próprio professor aplicar a prova, ficar com ela para compreendê-la melhor, corrigi-la e iniciar um processo de análise sobre o significado do desempenho dos seus alunos, tudo isso é feito a partir de um planejamento que não foi realizado por ele, a partir de itens que ele não criou e usando uma interpretação apresentada a ele de forma incompleta.

A forma como a Provinha Brasil é utilizada depende de cada rede. Em algumas, assim que os instrumentos são recebidos, eles são enviados para as escolas, que decidem quando devem aplicá-los e como utilizar seus resultados. Em outras redes, repete-se o que o governo federal faz com o Saeb: a Secretaria marca a data de aplicação, percorre as escolas aplicando os testes, coleta as folhas de resposta, faz a 
correção, analisa os resultados e só depois os discute com as escolas, normalmente fixando metas que devem ser atingidas por cada uma. Assim, um instrumento que deveria ser autonomamente utilizado pelas escolas pode, em alguns casos, repetir o esquema do Saeb e se transformar em mais um teste com o objetivo de controlar a escola e seus professores.

Com o Pacto Nacional de Alfabetização na Idade Certa (Pnaic), que será discutido mais à frente, a Provinha Brasil passa a ser obrigatória em todos os municípios que a ele aderirem. Além disso, os resultados de cada rede devem ser inseridos em um software que será disponibilizado pelo Inep e que permitirá ter um panorama nacional, escola por escola, do desempenho dos alunos. Aumenta-se a pressão por resultados envolvendo crianças muito jovens, sem que se tenha estudado os impactos que isso pode trazer ao seu desenvolvimento.

\section{AS AÇÕES DO GOVERNO FEDERAL QUE UTILIZAM OS RESULTADOS DAS AVALIAÇÕES}

Nos dois próximos tópicos, discutem-se o Plano de Desenvolvimento da Educação (PDE), o principal programa educacional do governo federal e um de seus componentes, o Pnaic, buscando compreender como os resultados dos testes avaliativos os influenciaram.

\section{PLANO DE DESENVOLVIMENTO DA EDUCAÇÃO (PDE)}

O PDE constitui-se de um conjunto de ações e programas voltados para a educação básica e superior desenvolvidos pelo MEC. Lançado em 2007, o programa possui seis pilares (BRASIL, 2011), destacando-se dois deles: responsabilização, que o texto apresenta como uma tradução de accountability, afirmando que, se a educação é um direito de todos e dever do Estado e da família, deve-se responsabilizar os que não garantem esse direito, sobretudo a classe política; mobilização social, fundamental para acompanhar e fiscalizar as ações educacionais, sendo que para que isso aconteça deve haver transparência no trato das questões ligadas à educação e nas políticas destinadas a seu desenvolvimento. 
O instrumento legal que normatizou o PDE foi o Plano de Metas Compromisso Todos pela Educação, que nada mais é do que a explicitação de como ocorrerão as transferências voluntárias da União para os estados e os municípios e em que áreas o MEC prestará assistência técnica e financeira. Sob a justificativa da necessidade de implementar o regime de colaboração entre os entes federados, é estabelecido um compromisso, de que tomam parte a União, os estados e os municípios, com base em 28 diretrizes definidas pelo governo federal que garantiriam a melhoria da educação básica (BRASIL; FUNDO DAS NAÇÕES UNIDAS PARA A INFÂNCIA, 2007).

Claramente, o documento impõe aos sistemas de ensino uma série de atribuições que lhes deveriam ser próprias, e sobre as quais a União não deveria ter ingerência, pois o que se deveria buscar seria um regime de colaboração. Além disso, associa o Ideb ao leme que deve guiar as ações desses sistemas, tornando-o, assim, o indicador da qualidade educacional. É importante destacar a limitação desse indicador, pois ele se refere apenas às medidas de desempenho em Língua Portuguesa e Matemática na Prova Brasil e do fluxo escolar, parcelas importantes, mas não determinantes, no conjunto de fatores que impactam uma educação de qualidade.

Com relação a aspectos educacionais propriamente ditos, das 28 diretrizes, apenas três se relacionam com o tema, com destaque àquela que estabelece uma meta para que a alfabetização esteja concluída até os oito anos de idade, equivalente ao final do $3^{\circ}$ ano do ensino fundamental, algo que Soares (2010) considera possível, e que garantiria, em tese, a possibilidade de desenvolvimento de novas habilidades nos anos seguintes a essa etapa de ensino. No entanto, a diretriz impõe a realização de um exame para aferir se a alfabetização ocorreu ou não. Essa imposição é colocada parcialmente em prática com o lançamento do Pnaic.

O que chama a atenção no Decreto é que por trás de um compromisso, um simples acordo envolvendo os entes da federação, seja imposta a seus signatários uma série de obrigações fixadas pela União. Poder-se-ia argumentar que como o compromisso é de natureza voluntária, quem estiver 
em desacordo com seus termos tem a opção de não o assinar. No entanto, o Art. $8^{\circ}$ do Decreto abre a possibilidade para que a União, unilateralmente, se exima de colaborar com o ente que deixar de firmá-lo. O fato é que todos os estados e municípios, sem exceção, firmaram esse compromisso. Mesmo porque nenhum ente da federação tem condições de dispensar os recursos federais que podem vir a ser transferidos, nem tampouco deixar de assumir o compromisso público de melhorar a educação sob sua responsabilidade.

\section{O PACTO NACIONAL DE ALFABETIZAÇÃO NA IDADE CERTA (PNAIC)}

Lançado em julho de 2012, com investimentos previstos de R \$ 3,3 bilhões, o Pnaic é um programa com o objetivo de garantir que todas as crianças estejam alfabetizadas até os oito anos de idade, ao final do $3^{\circ}$ ano do ensino fundamental.

Ele possui dois componentes principais: um curso de formação em serviço para cerca de 360 mil professores em atuação no chamado ciclo de alfabetização, aquele que compreende do $1^{\circ}$ ao $3^{\circ}$ ano do ensino fundamental, e a aplicação de testes para verificar o estágio da alfabetização dos alunos. Os entes da federação que quiseram aderir ao pacto assinaram compromisso envolvendo as duas ações do programa.

O curso de formação em serviço, primeiro componente do Pnaic, ocorrerá em diversos momentos durante o período 2013-2014, com ênfase em Língua Portuguesa, no primeiro ano, e em Matemática, no segundo ano. O segundo componente são dois testes para acompanhar a evolução da aprendizagem. A primeira testagem ocorre no início e no final do $2^{\circ}$ ano do ensino fundamental pela Provinha Brasil. Como já comentado antes, até 2012 esses testes eram utilizados apenas por aquelas redes que o quisessem, mas, a partir da adesão ao Pnaic, todas são obrigadas a realizá-lo, enviando seus resultados ao Inep. Além disso, a partir de 2014, tem sido utilizada a ANA para testar os alunos no final do $3^{\circ}$ ano do ensino fundamental, último ano do ciclo de alfabetização.

Com as novas ações do Pnaic, os alunos dos anos iniciais do ensino fundamental, de duração de cinco anos, serão 
testados quatro vezes pelo governo federal: no $2^{\circ}$ ano, por duas vezes, com a Provinha Brasil, no $3^{\circ}$ ano com a ANA e no $5^{\circ}$ ano com a Prova Brasil, todos de forma censitária. Um enorme esforço que vai mobilizar toda a comunidade escolar.

Outra inovação do Pacto é a instituição da premiação por desempenho, estando previstos recursos da ordem de $R \$ 500$ milhões para premiar as escolas que apresentarem os maiores progressos, podendo uma parte desse valor ser destinada à premiação da equipe escolar. Assim, o governo federal aproxima-se de outras iniciativas que também premiam a performan$c e$ das escolas, provavelmente na expectativa de que, com esse bônus, os professores se esforcem mais para conseguir que seus alunos obtenham desempenhos melhores.

Alguns aspectos dos programas de formação continuada desenvolvidos pelo governo federal merecem ser discutidos. Primeiro é um programa pontual, que tem por objetivo alinhar os docentes com as "últimas decisões em matéria de política educacional dos governos" (LUCIO, 2010, p. 51).

O segundo aspecto, relacionado a uma possível razão para que programas federais de formação continuada sejam pouco efetivos, tem relação com a elevada rotatividade da carreira docente. Existem estudos (HORTA NETO, 2013) mostrando uma rotatividade média anual de $30 \%$ da equipe docente das escolas públicas de ensino fundamental, ou seja, de cada dez professores que estão cadastrados em um determinado ano em uma escola, somente sete serão novamente docentes nessa mesma escola no ano seguinte. Em alguns estados e em algumas redes, essa rotatividade supera $60 \%$, e chega a ser maior na rede privada, mostrando tratar-se de um problema envolvendo a carreira docente como um todo, e não problema da rede pública. Quando se compara o intervalo de cinco anos, entre 2007 e 2012, a rotatividade nacional média dos docentes nas escolas públicas atinge patamares alarmantes: $43 \%$ para a rede estadual e $66 \%$ para a municipal.

Quando a rotatividade apresentada nesse estudo é comparada com estudos produzidos sobre a realidade americana, a rotatividade nas escolas brasileiras impressiona. As pesquisas nos Estados Unidos mostram que 30\% dos novos professores abandonam a profissão depois de cinco anos (INGERSOLL, 2001), e 
que em estados como o Texas, anualmente, entre $11 \%$ e $18 \%$ dos professores deixam a profissão, e entre $6 \%$ a $10 \%$ mudam de escola, sendo que a maior porcentagem refere-se a professores com até dois anos de formados (HANUSHECK; KAIN; RIVKIN, 1999).

Com uma rotatividade nos patamares em que se encontram, os programas de formação continuada de professores, complexos por serem gerenciados de Brasília, e de longa duração, não podem limitar-se a um único ciclo, pois sempre haverá um novo contingente de profissionais que não participaram desses programas. Dessa forma, os mesmos programas teriam que ser oferecidos por vários anos, ou então deveriam ser de tal forma estruturados que permitissem às secretarias continuar essa tarefa por conta própria. Nesse caso, esbarra-se em problemas de falta de pessoal especializado para levar a cabo essa tarefa.

Ao analisar o material desenvolvido pelo Pnaic, verifica-se que ele é essencialmente um curso sobre o processo de alfabetização, com suas técnicas e estratégias, algo que deveria fazer parte de qualquer curso de formação de professores. Como os professores em formação não têm tido a possibilidade de se aprofundar nesse tema durante a graduação, devido a problemas estruturais de seus cursos, fica a lacuna. Não seria mais produtivo o MEC atuar mais fortemente nos cursos superiores de formação de professores, já que, pela legislação, a União é que tem responsabilidade sobre a educação superior? Se isso fosse feito, a lacuna seria diminuída e permitiria a discussão com os outros entes da federação de programas mais simples, mas nem por isso de menor qualidade, voltados a temas específicos que pudessem ser desenvolvidos localmente. Da forma como os programas estão atualmente estruturados, a formação continuada está voltada para a complementação de falhas na formação inicial.

Pelos dados apresentados, fica claro que os resultados dos testes que vêm sendo aplicados nos últimos 25 anos não foram utilizados para o desenvolvimento dos dois programas analisados. Buscou-se, isso sim, instituir metas de desempenho.

Na seção a seguir, serão apresentadas evidências sobre ações que estão acontecendo nas escolas no sentido de buscar 
aumentar o desempenho dos alunos nos testes, sem necessariamente melhorar suas aprendizagens.

\section{A DISCUSSÃO DA QUALIDADE EDUCACIONAL NA MÍDIA ELETRÔNICA ESCRITA}

Como uma das premissas do accountability é que, com a exposição pública dos resultados dos testes de desempenho, haja uma mobilização da sociedade em busca da melhoria da escola, surgiu o questionamento de como a mídia eletrônica estaria tratando os resultados desses testes. Para isso, entre 10 de janeiro de 2009 e 11 de outubro de 2012, foram coletadas matérias disponibilizadas na internet, como artigos de jornais, revistas e textos de sites e blogs. Isso foi feito com a utilização da ferramenta "Alerta", do Google, em uma pesquisa com as seguintes expressões-chave: avaliação educacional, avaliação da educação, educational evaluation, evaluación educativa, evaluación de la educación, Prova Brasil, Provinha Brasil, sistema nacional de avaliação da educação básica, Saeb. Além disso, foi utilizado também o clipping de notícias do Movimento Todos pela Educação e o do Inep.

No total, foram analisados 2.100 links, apresentados no Quadro 1, no qual estão classificados os textos coletados em quatro categorias: "avaliações", "julgamento do resultado obtido”, "responsável pelo resultado obtido” e "preparação para os testes". 
QUADRO 1 - Frequência das matérias coletadas no período entre 10 de janeiro de 2009 e 11 de outubro de 2012, utilizando a ferramenta "Alertas do Google", quanto à classificação em temas gerais e específicos

\begin{tabular}{|c|c|c|}
\hline TEMA GERAL & TEMA ESPECÍFICO & FREQUÊNCIA \\
\hline \multirow{9}{*}{ 1. Avaliações } & Saeb, Prova Brasil e Ideb & 635 \\
\hline & Enem & 493 \\
\hline & Avaliações estaduais & 165 \\
\hline & Provinha Brasil & 174 \\
\hline & Prova ABC & 46 \\
\hline & Avaliações municipais & 35 \\
\hline & Avaliações privadas & 5 \\
\hline & Crítica à avaliação & O \\
\hline & Subtotal & 1.553 \\
\hline \multirow{3}{*}{$\begin{array}{l}\text { 2. Julgamento do } \\
\text { resultado obtido }\end{array}$} & Melhora da nota (desempenho bom) & 175 \\
\hline & Queda da nota (desempenho ruim) & 171 \\
\hline & Subtotal & 346 \\
\hline \multirow{5}{*}{$\begin{array}{l}\text { 3. Responsável pelo } \\
\text { resultado obtido }\end{array}$} & Professora e equipe escolar & 169 \\
\hline & Recursos & 86 \\
\hline & Equipe da secretaria & 49 \\
\hline & Curso (secretaria, particulares, on-line) & 41 \\
\hline & Subtotal & 345 \\
\hline \multirow{3}{*}{$\begin{array}{l}\text { 4. Preparação para os } \\
\text { testes }\end{array}$} & Secretarias & 132 \\
\hline & Interna à escola & 11 \\
\hline & Subtotal & 143 \\
\hline \multicolumn{2}{|l|}{ Total } & 2.387 \\
\hline
\end{tabular}

Fonte: Elaboração do autor

Note-se que, como um mesmo texto poderia tratar de diferentes temas, a frequência total foi de 2.387, superior aos 2.100 links analisados. Por questão de espaço, apenas parte do Quadro 1 será tratado. Para uma discussão mais detalhada, conferir Horta Neto (2013).

A primeira observação é que dos 2.100 links, nenhum deles apresentava críticas aos testes avaliativos no Brasil. No máximo, o que se encontrou foram sugestões de aprimoramento ao sistema adotado, passando uma imagem de que existiria uma unanimidade com relação a eles.

O tema mais citado, com 1.553 registros, trata das avaliações em geral, e, dentro dele, os mais citados referem-se 
ao Ideb, ao Saeb ou à Prova Brasil, recebendo 635 referências. A maior parte desses registros versa sobre o Ideb, informando o resultado alcançado, comparando-o com os anteriores e tecendo comentários sobre os desempenhos em Língua Portuguesa e Matemática. Quanto ao Saeb e à Prova Brasil, a maior parte dos textos discorre sobre a preparação para a aplicação dos testes e sobre suas realizações. No geral, a principal característica dos textos ligados a esse tema é ser de natureza informativa.

A respeito da Provinha Brasil, que recebeu 174 citações, apesar de ser um teste, à época da pesquisa, que permitia a cada escola aplicá-lo e corrigi-lo, as matérias produzidas pelas diversas mídias mostram que, gradativamente, as Secretarias de Educação assumem o controle da aplicação, da apuração e da divulgação dos resultados, utilizando para isso julgamentos de valor e o ranqueamento de escolas com base em níveis definidos pelo Inep para classificar os desempenhos dos alunos.

No caso das avaliações próprias, além dos testes elaborados pelos estados, as matérias apontaram o crescente número de municípios que utilizam essa estratégia a partir de 2011, indicando que 35 municípios passaram a utilizá-la, seja produzindo instrumentos localmente ou adquirindo-os de empresas e instituições especializadas. Juntamente com os testes, os municípios desenvolvem também indicadores, tomando como base a metodologia do Ideb. Apesar de as notícias tratarem de um número pequeno do total de 5.568 municípios brasileiros, o que se percebe é uma crescente utilização dessa estratégia. O tempo gasto nas escolas, na aplicação dos testes do município, do governo estadual e do federal e na preparação dos alunos para aumentar seu desempenho nesses testes, principalmente na forma de simulados, vem aumentando significativamente e deve estar tomando uma parcela importante do tempo que deveria ser dedicado à aprendizagem.

Com 345 referências, encontram-se as matérias que mostram quais seriam os responsáveis pelos resultados obtidos, fossem bons ou ruins. Atribui-se, em sua maioria, aos professores e à equipe escolar a responsabilidade pelos bons resultados, associando à função docente uma imagem messiânica, 
relacionada a um dom para educar, e à escola como o templo sagrado do saber, não como um local de disputas e conflitos. As matérias ressaltam a dedicação e o empenho dos professores e o espírito de equipe dos profissionais da escola em torno do objetivo de garantir a aprendizagem dos estudantes como responsáveis pelo sucesso da escola. Esses fatores superariam todo tipo de obstáculos, principalmente a falta de recursos, os baixos salários e as condições sociais adversas das comunidades em que as escolas estão localizadas.

O tema "preparação para os testes" envolveu matérias que tratavam explicitamente de estratégias utilizadas pelas secretarias ou pelas escolas para melhorar o desempenho dos alunos na Prova Brasil, aumentando, assim, seu Ideb. O total de referências coletadas representaram redes de ensino que congregam, no ensino fundamental regular, 4.300 escolas de ensino fundamental onde estão matriculados quase 1,5 milhões de alunos, representando $6 \%$ do total de alunos matriculados nessa etapa de ensino e que estão localizadas nas regiões geográficas mais pobres do Brasil. Fica patente nos textos que a preocupação não é com o aprendizado das crianças e dos jovens, e sim em elevar o valor do Ideb para, dessa forma, demonstrar que o que vem sendo feito pelos governos e pelas escolas está dando resultado. Essa preocupação com o Ideb demonstra que, de certa forma, o governo federal está conseguindo mobilizar, pelo menos, a classe política para melhorar os indicadores educacionais.

É preciso deixar claro que é possível, em algumas situações específicas, utilizar simulados como uma das possíveis estratégias que o professor tem a seu dispor para trabalhar alguns aspectos de determinada disciplina. Mas essa estratégia, para ser efetiva no sentido de aprimorar determinados aspectos do que se quer desenvolver, tem de ter relação com a realidade de sala de aula: deve ser preparada pelo professor, dentro de determinado contexto, e tendo por base seu conhecimento sobre o conjunto de seus alunos. Caso contrário, o teste acaba apresentando o mesmo caráter dos simulados utilizados para preparar os alunos do ensino médio para o Enem, em seu papel de vestibular nacional. Nesse caso, os alunos buscam individualmente estratégias para obter uma 
classificação mais alta que a de seus concorrentes, garantindo, assim, uma vaga no curso e na universidade escolhidos. Passada essa situação, e tendo sucesso em seu intento, pouco fica do que foi estudado, e o jovem, em pouco tempo, se esquece de grande parte do conteúdo utilizado para se preparar para o exame. Nesse caso, não houve aprendizagem significativa, pois tudo o que foi estudado só fazia sentido para garantir a vaga. No caso de testes como a Prova Brasil, o que seria de se esperar não é a busca de uma melhor classificação, mas sim a captação de informações que ajudassem a desenhar um quadro representativo da realidade educacional brasileira, para assim poder agir no sentido de melhorá-la. Da forma como parece que os simulados estão ocorrendo, os resultados que vêm sendo alcançados podem estar mascarando a realidade que se quer conhecer pelos testes.

Assim como no caso das secretarias de educação, algumas escolas também desenvolvem, por iniciativa própria, simulados para preparar seus alunos para o teste nacional. No caso das escolas, as matérias são mais escassas e foram colhidas na maior parte das vezes de blogs mantidos por elas ou por algum professor. Um dos casos descreve uma escola em um pequeno município do estado de Santa Catarina onde os professores afirmam que realizaram simulados a cada 15 dias. Principalmente nesse caso existe grande possibilidade de o ensino estar todo centrado na preparação para o teste.

Mesmo que se considere que seja necessário relativizar as informações obtidas a partir de matérias publicadas na internet, já que poderiam não apresentar dados fidedignos, a quantidade de alunos envolvidos no processo e a quantidade de depoimentos em favor da preparação para o teste não podem esconder que essa realidade é mais presente do que se poderia imaginar.

\section{CONSIDERAÇÕES FINAIS}

Desde os primeiros testes, tem-se produzido números com pouca relação com a prática pedagógica. Esses números isoladamente têm pouco significado para a escola, pois seu objetivo é buscar alternativas para garantir a aprendizagem de seus 
alunos. Essa aprendizagem depende de outros fatores que não apenas um número que reflita o resultado de um teste, teste esse limitado àquilo que pode ser medido para algumas, não para todas, as áreas do conhecimento do currículo escolar e a um subconjunto de possibilidades para se elaborar um item, cada uma delas trazendo diferentes dificuldades.

Assim, como parece pouco provável que uma quantidade grande de escolas consiga apropriar-se dos resultados, apesar dos mais de 20 anos de tentativas para melhor expressá-los, provavelmente o problema esteja com o uso inadequado dos resultados dos testes avaliativos. Isso porque, inicialmente, esses instrumentos foram desenhados para avaliar políticas educacionais, evoluíram para avaliar sistemas educacionais e, sem que se alterassem seus instrumentos nem a forma como eram desenvolvidos, passou-se a querer que as escolas utilizassem seus resultados para orientar seu trabalho pedagógico. Talvez os testes avaliativos possam ser úteis para a comunidade escolar, caso ela participe ativamente no desenvolvimento dos instrumentos e na análise dos resultados obtidos, algo que se procurou nos anos iniciais do Saeb, mas foi abandonado depois. Com isso, não se quer afirmar que as medidas realizadas não tenham importância alguma, mas sim que têm, no geral, pouca capacidade de influenciar o trabalho pedagógico da escola.

Por outro lado, nos últimos anos, tem sido veiculada uma forte mensagem de que aumentar o número de testes é um bom caminho para aprimorar as aprendizagens. A prova disso é o aumento crescente do número de estados que estão testando seus alunos, repetindo os mesmos procedimentos dos testes federais sobre as mesmas escolas. A única justificativa plausível para ações como essa é a de aumentar a pressão em busca de desempenhos maiores, algo que não necessariamente significa uma melhoria na aprendizagem. Além disso, o próprio governo federal tem aumentado o número de testes e a abrangência dos existentes.

Esta pesquisa encontrou evidências da crescente utilização de estratégias de aplicar simulados às vésperas da aplicação dos testes, denotando uma clara preocupação com os resultados, e não com os processos educacionais. Dessa forma, pode es- 
tar ocorrendo um estreitamento do currículo escolar àquilo que está sendo testado.

Por fim, apesar da grande ênfase dada pelo governo federal aos testes, o principal uso que se faz de seus dados é como auxiliar no processo de tomada de decisões relativas às transferências voluntárias da União. Com isso, pode-se estar estimulando apenas a busca por resultados, colocando os processos educacionais, que garantiriam uma aprendizagem significativa, em segundo plano.

\section{REFERÊNCIAS}

AFONSO, Almerindo J. Estado, mercado, comunidades e avaliação: esboço para uma rearticulação crítica. Educação e Sociedade, Campinas, v. 20, n. 69, p. 139-164, 1999.

. Avaliação educacional: regulação e emancipação. São Paulo: Cortez, 2005.

BONAMINO, Alícia C.; SOUZA, Sandra Z. Três gerações de avaliação da educação básica no Brasil: interfaces com o currículo da/na escola. Educação e Pesquisa, São Paulo, v. 38, n. 2, p. 373-388, 2012.

BRASIL. Instituto Nacional de Estudos e Pesquisas Educacionais Anísio Teixeira. Resultados das edições anteriores. Brasília, DF: Inep, 2011. Disponível em: <http://portal.inep.gov.br/web/saeb/resultados>. Acesso em: dez. 2014.

BRASIL. Ministério da Educação. O Plano de Desenvolvimento da Educação: razões, princípios e programas. Brasília: MEC, 2011.

. Elementos conceituais e metodológicos para a definição dos direitos de aprendizagem e desenvolvimento do ciclo de alfabetização $\left(1^{\circ}, 2^{\circ}\right.$ e $3^{\circ}$ anos) do ensino fundamental. Brasília: MEC, 2012.

BRASIL. Ministério da Educação. Instituto Nacional de Estudos e Pesquisas Educacionais Anísio Teixeira.; FUNDO DAS NAÇÕES UNIDAS PARA A INFÂNCIA. Aprova Brasil: o direito de aprender. Brasília: Unicef, 2007.

BROOKE, Nigel; CUNHA, Maria Amália A.; FALEIROS, Matheus. A avaliação externa como instrumento da gestão educacional dos estados. São Paulo: Game/FAE/ UFMG, 2011.

FUNDO DAS NAÇÕES UNIDAS PARA A INFÂNCIA; BRASIL. Ministério da Educação; UNIÃO DOS DIRIGENTES MUNICIPAIS DE EDUCAÇÃO. Redes de aprendizagem: boas práticas de municípios que garantem o direito de aprender. Brasília: Unicef, 2008.

GATTI, Bernadete A. Avaliação educacional: pontuando uma história de ações. EccoS revista científica, São Paulo, v. 4, n. 1, p. 17-41, jun. 2002.

HANUSHECK, Eric A.; KAIN, Jonh F.; RIVKIN, Steven G. Do higher salaries buy better teachers? National Bureau of Economic Research, Washington, 1999. 
HORTA NETO, João Luiz. Avaliação externa de escolas e sistemas: questões presentes no debate sobre o tema. Revista Brasileira de Estudos Pedagógicos, Brasília, v. 91, n. 227, p. 84-104, jan./abr. 2010.

As avaliações externas e seus efeitos sobre as políticas educacionais: uma análise comparada entre a União e os Estados de Minas Gerais e São Paulo. 2013. Tese (Doutorado em Política Social) - Instituto de Ciências Humanas, Departamento de Serviço Social, Brasília. 2013.

INGERSOLL, Richard M. Teacher turnover and teacher shortages: an organization analysis. American Educational Research Jounal, Washington, DC, v. 38, n. 3, p. 499-534, 2001.

KORTE, Robert C.; NASH, Beverly E. Review of the Sistema Nacional de Avaliação da Educação Básica (Saeb). Brasilia: Inep, 1995.

LUCIO, Elizabeth O. Tecendo os fios da rede: o Programa Pró-Letramento e a tutoria na formação continuada de professores alfabetizadores da educação básica. 2010. Dissertação (Mestrado em Educação) - Faculdade de Educação, Universidade Federal do Rio de Janeiro, Rio de Janeiro, 2010.

OLIVEIRA, Romualdo P.; ARAÚJO, G. C. Qualidade do ensino: uma nova dimensão da luta pelo direito à educação. Revista Brasileira de Educação, São Paulo, n. 28, p. 13-35, jan./abr. 2005.

RAVITCH, Diane. The death and life of the graet american school system: how testing and choice are undermining education. Nova York: Basic Books, 2010.

Reign of error: the hoax of the privatization movement and the danger to america's public schools. Nova York: Alfred A. Knopf, 2013.

SAHLBERG, Pasi. Finnish lessons: what can the world learn from educactional change in Finland? Nova York: Teacher College Press, 2011.

SOARES, Magda B. Por uma alfabetização até os oito anos de idade. In: TODOS PELA EDUCAÇÃO. De otho nas metas 2010. São Paulo: Todos pela Educação, 2010. p. 14-17.

VIANNA, Heraldo M. Avaliação do rendimento de alunos de escolas da rede pública: um estudo em 15 capitais e 24 outras cidades. São Paulo: Fundação Carlos Chagas, 1990.

\section{JOÃO LUIZ HORTA NETO}

Doutor em Política Social e Mestre em Educação pela

Universidade de Brasília (UnB). Pesquisador do Instituto

Nacional de Estudos e Pesquisas Educacionais Anísio

Teixeira (Inep)

jlhorta@gmail.com

Recebido em: OUTUBRO 2013

Aprovado para publicação em: SETEMBRO 2014 